\title{
AREA ESTIMATION OF COTTON AND MAIZE CROPS IN PERAMBALUR DISTRICT OF TAMIL NADU USING MULTI DATE SENTINEL-1A SAR DATA \& OPTICAL DATA
}

\author{
Kumaraperumal Ramalingam ${ }^{1}$, Arun Balaji Ramathilagam ${ }^{2, *}$, Pugazhenthi Murugesan ${ }^{1}$ \\ ${ }^{1}$ Tamil Nadu Agricultural University, Coimbatore 641003, Tamil Nadu, India - (kumaraperumal.r, pugalsri243)@gmail.com \\ ${ }^{2}$ Indian Institute of Remote Sensing, Dehradun 248001, Uttarakhand, India - arunthilak95@gmail.com
}

\section{Commission III, WG III/10}

KEY WORDS: Cotton, Maize, Sentinel-1A, SAR, Area Estimation.

\begin{abstract}
:
This study was carried out to estimate the area of cotton and maize crops in Permabalur district of Tamil Nadu using microwave and optical data. Permabalur was selected as the study area, as it is the largest cotton and maize producing district in Tamil Nadu. The multi-temporal Sentinel-1A SAR data was acquired from 09th July, 2016 to 17th January, 2017 as it coincides with the crop calendar of these crops. Both the Vertical - Vertical (VV) and Vertical - Horizontal (VH) polarized data were compared. The cloud free Landsat 8 data acquired on 7th October 2016 was fused with the Vertical - Vertical (VV) and Vertical-Horizontal (VH) polarized data of 13th October and classified. Unsupervised classification approach was adopted to classify the cotton and maize pixels. The highest accuracy of $72.73 \%$ and $76.24 \%$ were achieved in VV polarization + Landsat 8 data and VH polarization + Landsat 8 data respectively. The cotton and maize areas were estimated to be 20,218 ha and 28,032 ha respectively. It is also evident that $\mathrm{VH}$ polarization fused with optical data is better in discriminating the cotton and maize crop than VV polarization fused with optical data.
\end{abstract}

\section{INTRODUCTION}

Remote Sensing plays a very important role in achieving the United Nations Sustainable Development Goal 2: Zero Hunger. Crop monitoring provides timely information about the crop conditions at various stages and helps to estimate area and yield at national and even village levels (Pazhanivelan et al., 2015). Yield information is very useful in checking the price fluctuations of food crops and monitoring the food reserves. The area estimates are useful in planning and policy making at various administrative levels. We need accurate data at various temporal and spatial scales to monitor the agricultural lands and the changes over time. Usually active sensors are preferred for crop monitoring as they have better accuracy than the optical data. But combining both the optical and SAR data gave better results (Forkuor, Conrad, Thiel, Ullmann, \& Zoungrana, 2014). The performance differs with the polarisation used for identifying the crops. The phenology of the crop also plays an important role in these kind of studies (Skriver, 2012). The nature of back scattering differs for crops with broad leaves and narrow leaves (Bargiel \& Herrmann, 2011). Broader leaf crops usually have higher backscattering than narrow leaf crops (Macelloni, Paloscia, Pampaloni, Marliani, \& Gai, 2001). The prime objective of this study is to combine optical and SAR data of various polarisations for cotton and maize area estimation and to extract the backscatter coefficients of these crops.

\section{MATERIALS AND METHODS}

\subsection{Study Area}

Perambalur district is a centrally located inland district of Tamil Nadu with a spread over of 1750 sq.kms. The climate is hot sub humid to semi-arid. The mean annual maximum and minimum temperature are $32.6^{\circ} \mathrm{C}$ and $22.2^{\circ} \mathrm{C}$ respectively. The area receives a mean annual rainfall of $908 \mathrm{~mm}$ out of which $475 \mathrm{~mm}$ is contributed by North East monsoon and $314 \mathrm{~mm}$ by South West monsoon. Black cotton soil, clay loam and red sandy soil are the predominant soil types of this district. Maize, Cotton, Sorghum, Onion, Tapioca, Paddy, Groundnut and Sesame are the major cultivated crops.

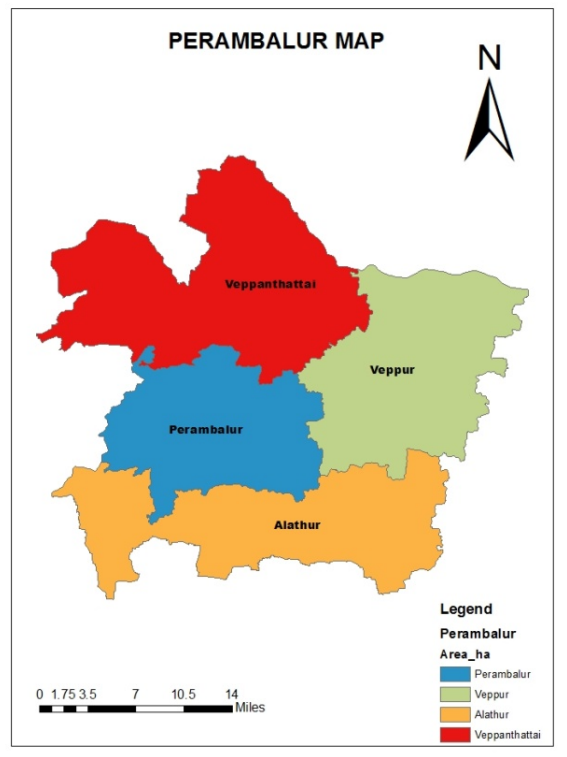

Figure 1. Map of the Study Area

* Corresponding author 


\subsection{Data Used}

In a country like India, where the agriculture is dependent on the monsoons, we need SAR data, which can penetrate through the clouds and help us with the crop monitoring. Sentinell-A, carrying a C-band radar system with VV (Vertical-Vertical) and $\mathrm{VH}$ (Vertical-Horizontal) polarization were obtained at twelve days interval and it was used for crop monitoring. The spatial resolution of the Sentinel-1A data is $20 \mathrm{~m}$. The Landsat 8 OLI data acquired on 7th October 2016 was chosen for the study, as it was cloud free. The resolution of Landsat 8 data is $30 \mathrm{~m}$. Most of the processing was done using SNAP and ERDAS Imagine.

\subsection{Methodology}

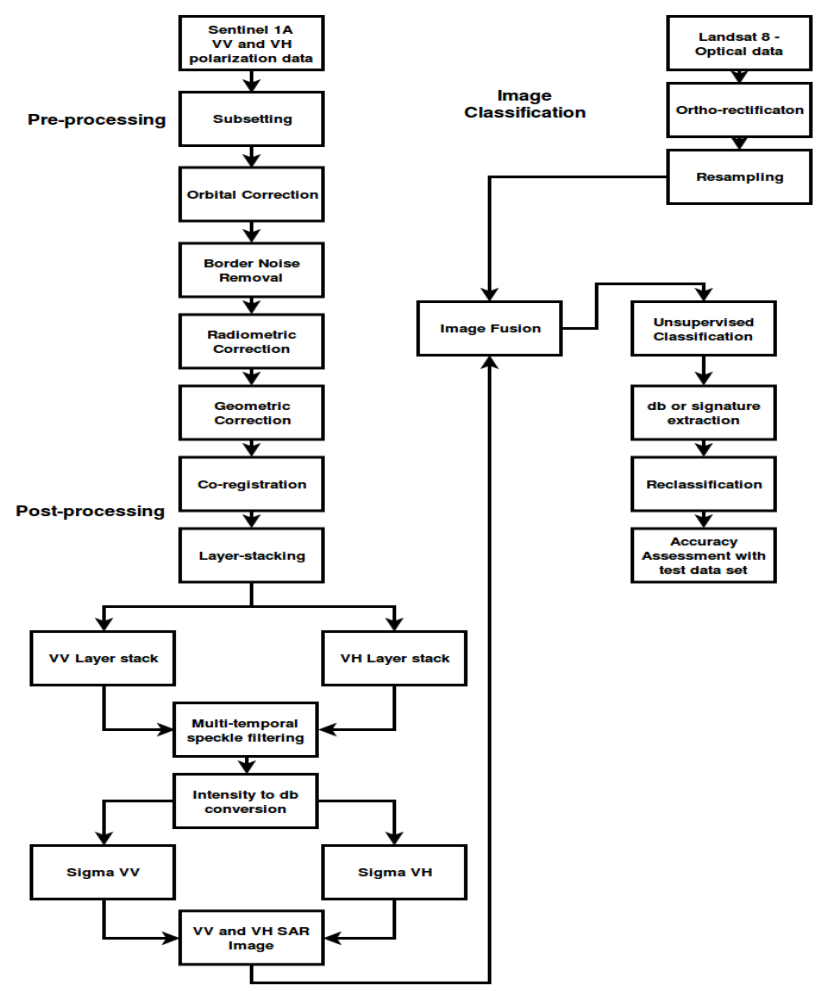

Figure 2. Methodology adopted

2.3.1 Pre-processing: The VV and VH polarized intensity bands were pre-processed to remove unwanted distortions and enhance the features in the scene. Subset of the study area was created and orbital correction was applied. All the 'no-values' pixels along the border were removed and then calibrated. The images were geometrically corrected to WGS 84 projection using range Doppler terrain correction method and resampled using nearest-neighbour algorithm.

2.3.2 Post-processing: Both the VV and VH polarized images were co-registered and stacked separately in the order from 02-August, 2016 to 17-January, 2017. After de-speckling, the intensity values of SAR images were converted to $\mathrm{dB}$ using the linear to $\mathrm{dB}$ conversion tool.
2.3.3 Ground Truth Collection: For training and validation, ground survey was conducted during January 2017. Totally, fifty-eight points were surveyed for maize (26 points) and cotton (32 points). Random sampling method was used to assign separate training $(50 \%)$ and validation $(50 \%)$ datasets from the ground reference data collected during the field observations. For all the classification methods, the same set of training samples and validation samples were maintained.

\begin{tabular}{|c|c|c|c|}
\hline Crops & $\begin{array}{c}\text { Training } \\
\text { Points }\end{array}$ & $\begin{array}{c}\text { Validation } \\
\text { Points }\end{array}$ & $\begin{array}{c}\text { Total } \\
\text { Points }\end{array}$ \\
\hline Cotton & 15 & 17 & 32 \\
\hline Maize & 16 & 10 & 26 \\
\hline
\end{tabular}

Table 1. Ground Truth Points collected for cotton and maize crops

2.3.4 Signature Extraction: The radar-backscattering coefficient $\left(\sigma^{0}\right)$ is a measure of crop biomass, plant height, water content, underlying soil, crop phenology etc. The SAR data collected during the cropping period were processed and analysed using the training pixels to derive the temporal backscattering coefficient $\left(\sigma^{0}\right)$ for Cotton and Maize.

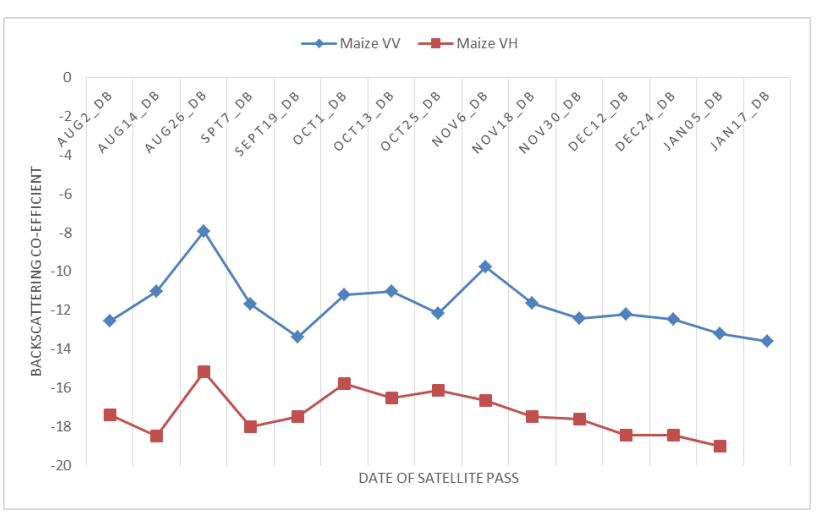

Figure 3. Mean temporal back scattering of Maize

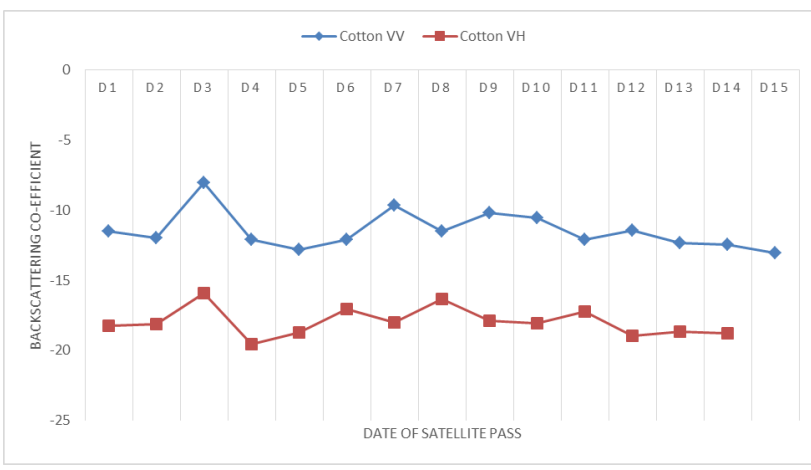

Figure 4. Mean temporal back scattering of Cotton

The minimum, maximum and mean temporal backscattering signature for Vertical-Vertical (VV) and Vertical-Horizontal (VH) polarized SAR data for cotton and maize were derived. The mean backscattering values for maize crop during the entire cropping period ranges from $-13.59 \mathrm{~dB}$ to $-7.91 \mathrm{~dB}$ and from - 
$19.03 \mathrm{~dB}-15.18 \mathrm{~dB}$ for $\mathrm{VV}$ and $\mathrm{VH}$ polarization respectively. For cotton crop, it ranges from $-13.06 \mathrm{~dB}$ to $-8.07 \mathrm{~dB}$ and from $-19.56 \mathrm{~dB}$ to $-15.92 \mathrm{~dB}$ for $\mathrm{VV}$ and $\mathrm{VH}$ polarized data respectively.

2.3.5 Image Classification: The combined K-means and hill-climbing algorithm was adopted for classification. All the combinations were separately processed and the clusters were properly matched with the ground truth training data and reclassified. The classified images were further evaluated for accuracy with validation data.

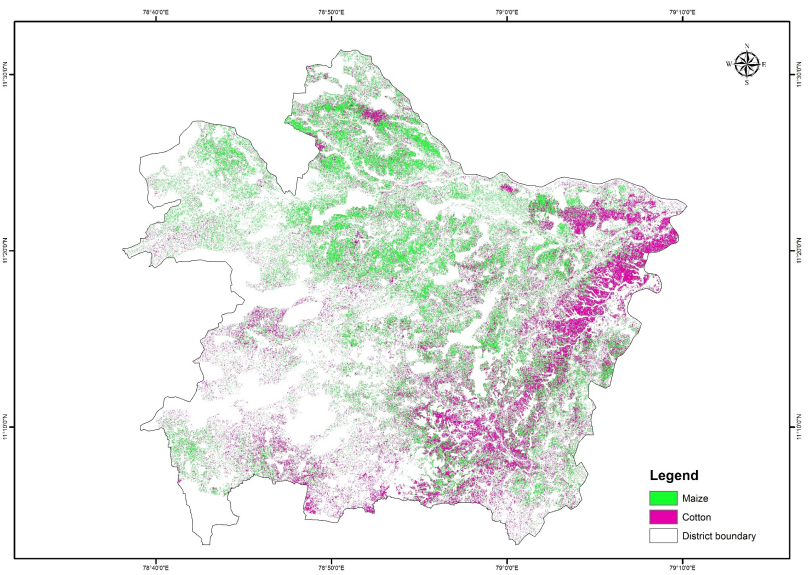

Figure 5. Classified image using unsupervised classification for VV polarization

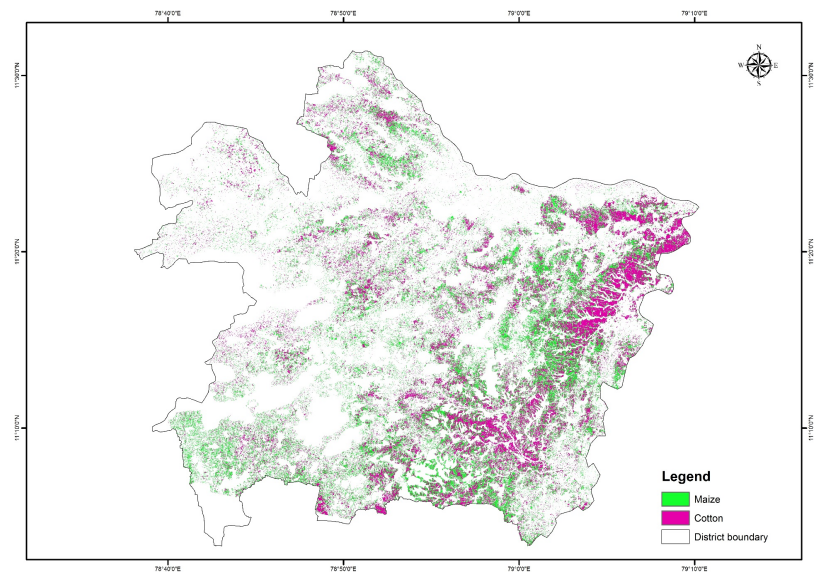

Figure 6. Classified image using unsupervised classification for VH polarization

2.3.6 Accuracy Assessment: Accuracy assessment was conducted with a total of 58 points (cotton- 32 points and maize-26 points) randomly spread over the study area. The overall accuracy, producer's and user's accuracies were determined. The overall accuracy for $\mathrm{VV}$ classified image is $60.87 \%$, for $\mathrm{VH}$ it is $64.29 \%$, for $\mathrm{VV} / \mathrm{VH}$ it is $52.94 \%$, for Landsat it is $48.65 \%$, for Landsat 8 and VV polarization fusion image it is $72.73 \%$ and for Landsat 8 and $\mathrm{VH}$ polarization fusion image it is $76.24 \%$.

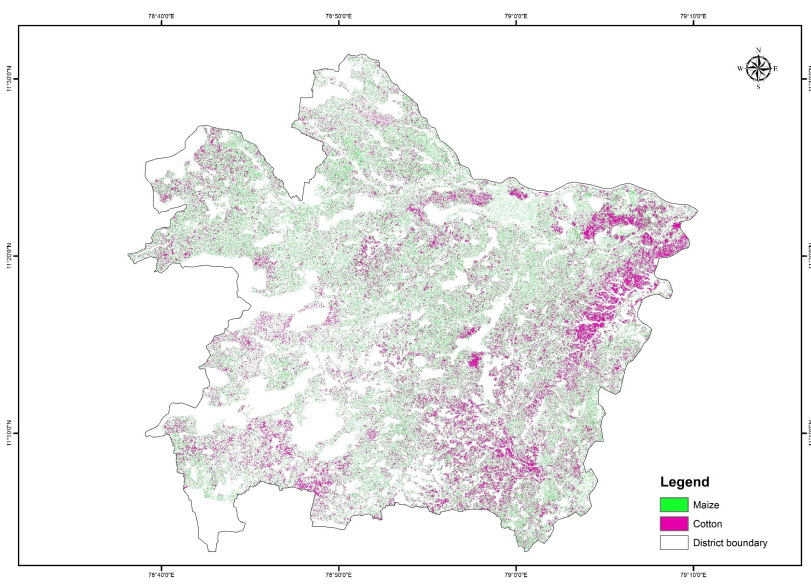

Figure 7. Classified image using unsupervised classification for $\mathrm{VV} / \mathrm{VH}$ polarization

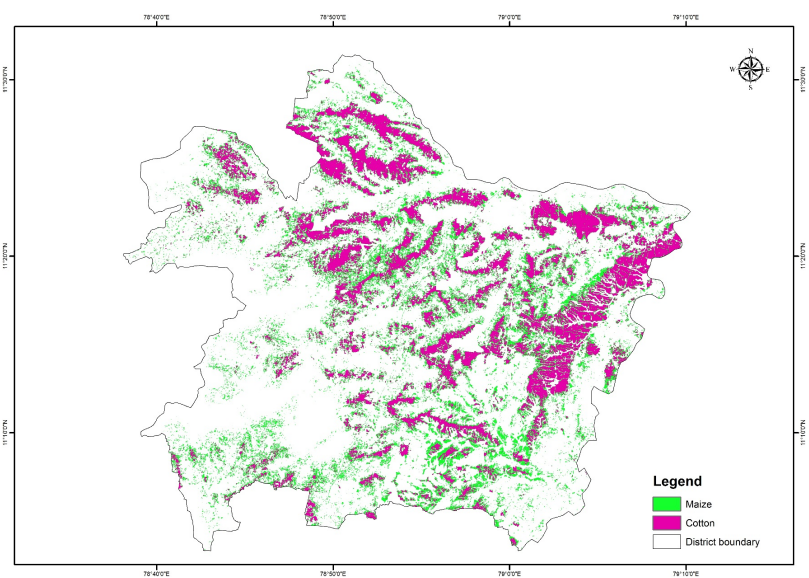

Figure 8. Classified image using unsupervised classification for Landsat 8

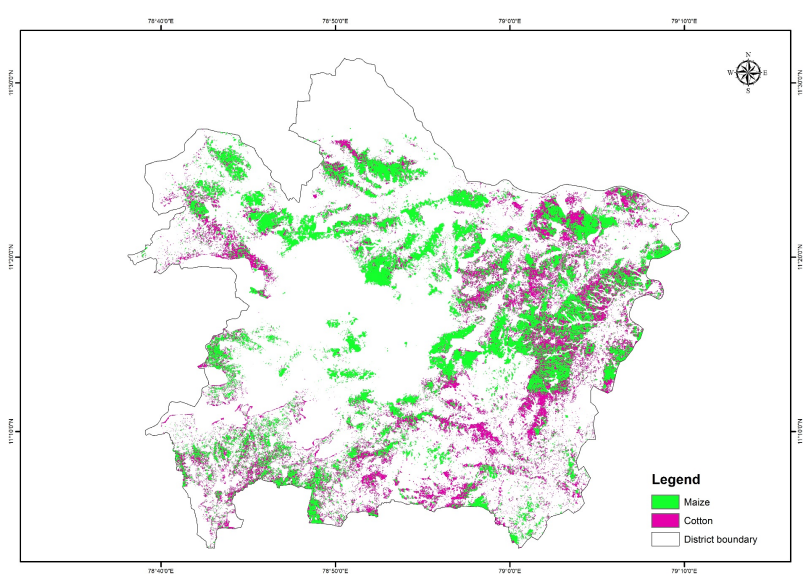

Figure 9. Classified image using unsupervised classification for Fusion Landsat 8 \& VV polarization 


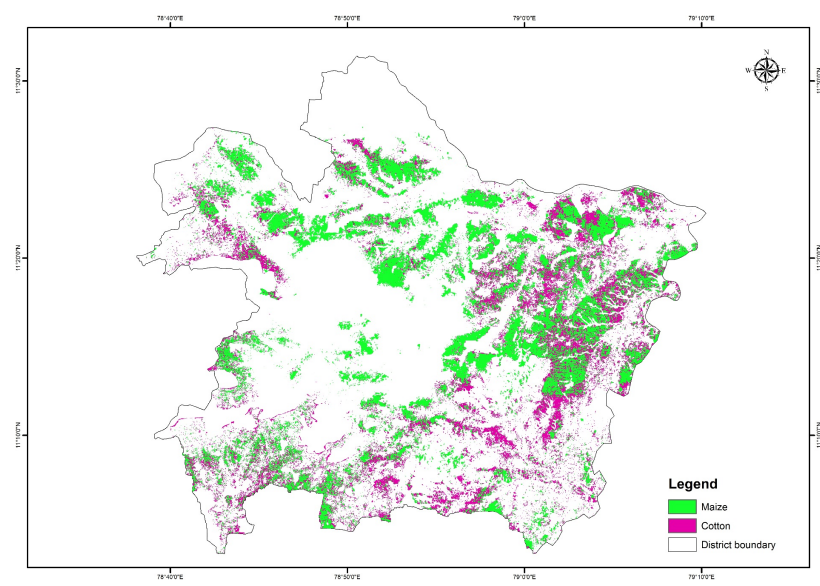

Figure 10. Classified image using unsupervised classification for Fusion Landsat $8 \&$ VH polarization

\begin{tabular}{|c|c|c|c|}
\hline & Parameters & $\begin{array}{c}\text { Overall } \\
\text { Accurac } \\
\mathbf{y} \\
\end{array}$ & $\begin{array}{c}\text { Kappa } \\
\text { Coefficien } \\
t\end{array}$ \\
\hline \multirow{3}{*}{ SAR data } & VV polarisation & 60.87 & 0.180 \\
\hline & VH polarisation & 64.29 & 0.220 \\
\hline & $\begin{array}{c}\mathrm{VV} / \mathrm{VH} \\
\text { polarization }\end{array}$ & 52.94 & -0.310 \\
\hline $\begin{array}{c}\text { Optical } \\
\text { data }\end{array}$ & Landsat 8 & 48.65 & -0.030 \\
\hline \multirow{2}{*}{$\begin{array}{l}\text { SAR and } \\
\text { optical } \\
\text { fused data }\end{array}$} & $\begin{array}{l}\text { Landsat } 8 \text { and } \\
\text { VV polarization }\end{array}$ & 72.73 & 0.451 \\
\hline & $\begin{array}{l}\text { Landsat } 8 \text { and } \\
\text { VH polarization }\end{array}$ & 76.24 & 0.492 \\
\hline
\end{tabular}

Table 2. Overall accuracy and Kappa Values for SAR and optical data

\section{RESULTS AND DISCUSSIONS}

\subsection{Radar Backscattering Signature}

The temporal backscattering coefficient $\left(\sigma^{0}\right)$ for cotton and maize are extracted using the training datasets. The mean backscattering values for cotton during the entire cropping period ranges from $-13.06 \mathrm{~dB}$ to $-8.07 \mathrm{~dB}$ and $-19.56 \mathrm{~dB}$ to $15.92 \mathrm{~dB}$ for $\mathrm{VV}$ and $\mathrm{VH}$ polarized data respectively and for maize it ranges from $-13.59 \mathrm{~dB}$ to $-7.91 \mathrm{~dB}$ and $-19.03 \mathrm{~dB}$ to $15.18 \mathrm{~dB}$ for $\mathrm{VV}$ and $\mathrm{VH}$ polarized data respectively.

\subsection{Crop Classification}

Unsupervised classification classified 22,039 ha of cotton and 24,810 ha of maize in VV polarized data, 20,287 ha of cotton and 21,091 ha of maize in VH polarization, 20,321 ha of cotton and 19,843 ha of maize in VV/VH polarization, 27,097 ha of cotton and 24,815 ha of maize in optical data, 19,068 ha of cotton and 28,772 ha of maize in VV polarization and landsat8 fused data and 20,218 ha of cotton and 28,032 ha of maize in VH polarization and landsat 8 fused data. The highest accuracy of $76.24 \%$ was achieved in SAR and optical image fused classified image.

\begin{tabular}{|c|c|c|c|}
\hline & Parameters & Maize(ha) & Cotton(ha) \\
\hline \multirow[b]{3}{*}{ SAR data } & VV polarisation & 24810 & 22039 \\
\hline & VH Polarisation & 21091 & 20287 \\
\hline & $\begin{array}{c}\mathrm{VV} / \mathrm{VH} \\
\text { polarization }\end{array}$ & 18843 & 20321 \\
\hline $\begin{array}{c}\text { Optical } \\
\text { data }\end{array}$ & Landsat 8 & 24815 & 27097 \\
\hline \multirow{2}{*}{$\begin{array}{c}\text { SAR and } \\
\text { optical } \\
\text { fused data }\end{array}$} & $\begin{array}{c}\text { Landsat } 8 \text { and } \mathrm{VV} \\
\text { polarization }\end{array}$ & 28772 & 19068 \\
\hline & $\begin{array}{c}\text { Landsat } 8 \text { and } \mathrm{VH} \\
\text { polarization }\end{array}$ & 28032 & 20218 \\
\hline
\end{tabular}

Table 3. Comparison of area for SAR and optical data

\section{CONCLUSION}

Thus, the area of cotton and maize were estimated using both SAR and optical data. $\mathrm{K}$ means clustering unsupervised classification technique was adopted to classify the cotton and maize pixels. The highest accuracy of $76.24 \%$ was achieved for $\mathrm{VH}$ and optical fused data where the area of maize and cotton were estimated to be 28,032 ha and 20,218 ha respectively. The temporal backscattering coefficients of cotton and maize were analysed throughout their vegetative and reproductive phases. This study can be further extended to estimate the yield of cotton and maize.

\section{REFERENCES}

Bargiel, D., \& Herrmann, S. (2011). Multi-Temporal LandCover Classification of Agricultural Areas in Two European Regions with High Resolution Spotlight TerraSAR-X Data. Remote Sensing (Vol. 3). https://doi.org/10.3390/rs3050859.

Forkuor, G., Conrad, C., Thiel, M., Ullmann, T., \& Zoungrana, E. (2014). Integration of Optical and Synthetic Aperture Radar Imagery for Improving Crop Mapping in Northwestern Benin, West Africa. Remote Sensing https://doi.org/10.3390/rs6076472.

Macelloni, G., Paloscia, S., Pampaloni, P., Marliani, F., \& Gai, M. (2001). The relationship between the backscattering coefficient and the biomass of narrow and broad leaf crops. Geoscience and Remote Sensing, IEEE Transactions on (Vol. 39). https://doi.org/10.1109/36.917914.

Pazhanivelan, S., Kannan, P., Christy Nirmala Mary, P., Subramanian, E., Jeyaraman, S., Nelson, A., ... Yadav, M. (2015). Rice crop monitoring and yield estimation through COSMO Skymed and TerraSAR-X: A SAR-based experience in India. International Archives of the Photogrammetry, Remote Sensing and Spatial Information Sciences - ISPRS Archives. https://doi.org/10.5194/isprsarchives-XL-7-W3-85-2015.

Skriver, H. (2012). Crop Classification by Multitemporal Cand L-Band Single and Dual-Polarization and Fully Polarimetric SAR. IEEE Transactions on Geoscience and Remote Sensing - IEEE TRANS GEOSCI REMOT SEN (Vol. 50). https://doi.org/10.1109/TGRS.2011.2172994. 